\title{
Physics of Stratocumulus Top (POST): turbulent mixing across capping inversion
}

\author{
S. P. Malinowski ${ }^{1,2}$, H. Gerber ${ }^{3}$, I. Jen-La Plante ${ }^{1}$, M. K. Kopec ${ }^{1}$, W. Kumala ${ }^{1}$, K. Nurowska ${ }^{1}$, P. Y. Chuang ${ }^{4}$, \\ D. Khelif ${ }^{5}$, and K. E. Haman ${ }^{1}$ \\ ${ }^{1}$ Institute of Geophysics, Faculty of Physics, University of Warsaw, Warsaw, Poland \\ ${ }^{2}$ Interdisciplinary Centre for Mathematical and Computational Modelling, University of Warsaw, Warsaw, Poland \\ ${ }^{3}$ Gerber Scientific Inc., Reston, VA, USA \\ ${ }^{4}$ Earth and Planetary Sciences, University of California, Santa Cruz, CA, USA \\ ${ }^{5}$ Department of Mechanical and Aerospace Engineering, University of California, Irvine, CA, USA
}

Correspondence to: S. P. Malinowski (malina@fuw.edu.pl)

Received: 8 February 2013 - Published in Atmos. Chem. Phys. Discuss.: 11 June 2013

Revised: 24 October 2013 - Accepted: 20 November 2013 - Published: 17 December 2013

\begin{abstract}
High spatial resolution measurements of temperature and liquid water content, accompanied by moderateresolution measurements of humidity and turbulence, collected during the Physics of Stratocumulus Top experiment are analyzed. Two thermodynamically, meteorologically and even optically different cases are investigated. An algorithmic division of the cloud-top region into layers is proposed. Analysis of dynamic stability across these layers leads to the conclusion that the inversion capping the cloud and the cloud-top region is turbulent due to the wind shear, which is strong enough to overcome the high static stability of the inversion. The thickness of this mixing layer adapts to wind and temperature jumps such that the gradient Richardson number stays close to its critical value. Turbulent mixing governs transport across the inversion, but the consequences of this mixing depend on the thermodynamic properties of cloud top and free troposphere. The effects of buoyancy sorting of the mixed parcels in the cloud-top region are different in conditions that permit or prevent cloud-top entrainment instability. Removal of negatively buoyant air from the cloud top is observed in the first case, while buildup of the diluted cloud-top layer is observed in the second one.
\end{abstract}

\section{Introduction}

Exchange processes between stratocumulus (Sc) clouds and the free troposphere (FT) above them have been intensively investigated in many research campaigns (e.g., Albrecht et al., 1988; Lenschow et al., 1988; Stevens et al., 2003; Bretherton et al., 2004). Despite the fact that marine stratocumulus is a relatively simple system - plane-parallel, warm cloud occupying the upper part of the well-mixed boundary layer above a homogeneous flat surface, and under an almost "rigid lid" temperature inversion of $\sim 10 \mathrm{~K}$ - the understanding of entrainment into the stratocumulus-topped boundary layer (STBL) from the free troposphere is limited. In a paper devoted to this subject Stevens (2002) writes: “... We posed two questions: (1) how well do we really understand entrainment and (2) does it really matter? The answer to the first question is 'not very well'. The answer to the second question is yes."

Consequently, estimates of the entrainment velocity are ambiguous. Consider the DYCOMS II field campaign (Stevens et al., 2003). Faloona et al. (2005) report three different values of entrainment velocity calculated from covariances of vertical velocity and conserved variables. All these values fall into the range of uncertainty of the entrainment velocity estimated from the boundary layer growth rate and large-scale subsidence. For the same campaign Gerber et al. (2005) estimated entrainment velocities from conditional sampling of cloud holes and from a flux jump approach. His 
estimates differ by a factor of 2, with conditional sampling giving higher values. Gerber et al. (2005) obtained maximum entrainment rates for flights 04 and 06, while Faloona et al. (2005) reported flights 02 and 03 as the most entraining. Using DYCOMS II data Lilly (2008) tested experimentally his modified flux closure formula, introduced for predicting entrainment (Lilly and Stevens, 2008), obtaining values of entrainment velocity closer to that of Faloona et al. (2005) than that of Gerber et al. (2005), but raised many doubts concerning mechanisms of the entrainment process. Ten years after Stevens (2002), in a review paper Wood (2012) writes: "A major unresolved question in stratocumulus dynamics is how the entrainment rate $w_{\mathrm{e}}$ at the top of the STBL relates to STBL turbulent dynamics .... The extent to which entrainment is controlled by the large eddies ... as opposed to small scale mixing processes and direct non-turbulent radiative/evaporative cooling ... is not fully understood."

The key to the problem is in understanding mixing across the entrainment interface layer (EIL) located between the FT and the STBL (e.g., Caughey et al., 1982; Nicholls and Turton, 1986; Lenschow et al., 2000; Gerber et al., 2005). Data from in situ measurements (e.g., Caughey et al., 1982; Nicholls, 1989; Lenschow et al., 2000; De Roode and Wang, 2007) and the results of numerical simulations (e.g., Moeng et al., 2005; Yamaguchi and Randall, 2008) clearly indicate that the top of Sc is located below the capping inversion and does not directly interact with the FT above. The thickness of the EIL, related to the distance between the cloud top and inversion, varies from a few meters to a few tens of meters (e.g., Haman et al., 2007; Kurowski et al., 2009; Katzwinkel et al., 2012), and differs for different Sc cases (Carman et al., 2012).

Data from the majority of field campaigns and numerical simulations are of too-poor resolution to infer the structural details of such thin EIL and neighboring layers. However, some general conclusions concerning mixing through a stably stratified capping inversion, resulting from theoretical considerations and large eddy simulations (LES), indicate that, in order to allow for entrainment, turbulence in the inversion must be excited. Inversion capping a typical marine stratocumulus is usually too strong to allow buoyancydriven turbulence, produced elsewhere, to break the barrier of potential energy and mix across the stably stratified layer. This means that at least locally the gradient Richardson number across the inversion has to exceed the critical value, as shown, e.g., by Wang et al. $(2008,2012)$ and Kurowski et al. (2009). Such a shear-generated turbulence in the EIL was observed in a great detail by Katzwinkel et al. (2012) in the course of several penetrations of Sc top performed with an Airborne Cloud Turbulence Observation System ACTOS (Siebert, 2006).

In this paper we continue investigations of the EIL and capping inversion. We examine in detail two very different cases of stratocumulus top, documented by means of high spatial resolution $(\sim 1 \mathrm{~m}$ or less) measurements of veloc-

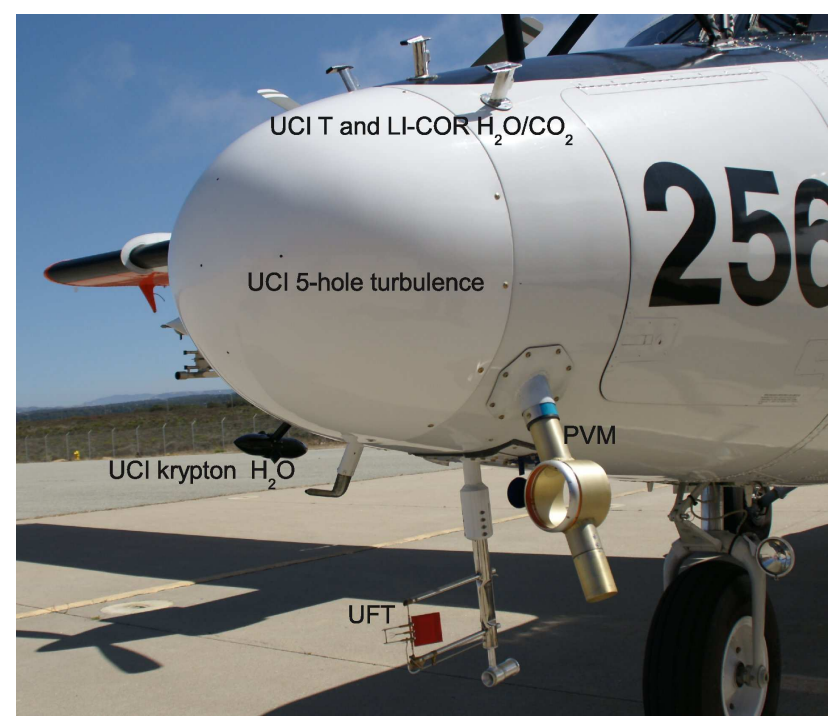

Fig. 1. Radome of CIRPAS Twin Otter research aircraft with fastresponse instruments used in POST.

ity fluctuations, temperature and liquid water content. Airborne data analyzed here were collected during the Physics of Stratocumulus Top (POST) research campaign performed in 2008. The paper is structured in the following way: information about the POST campaign and key instruments providing data for the analysis is in Sect. 2. Two contrasting stratocumulus cases, corresponding to research flights TO10 and TO13 (TO for "Twin Otter") are presented in Sect. 3. Data analysis and discussion of the results are presented in Sect. 4, and the main findings and working hypotheses are summarized in Sect. 5.

\section{POST: Physics of Stratocumulus Top research campaign}

POST was a research campaign held in the vicinity of Monterey Bay in July and August 2008 (Gerber et al., 2010; Carman et al., 2012; Gerber et al., 2013). High-resolution in situ measurements with a Center for Interdisciplinary RemotelyPiloted Aircraft Studies (CIRPAS) Twin Otter research aircraft were focused on a detailed study of processes occurring at the interface between the STBL and the FT. The aircraft was equipped for thermodynamics, microphysics, dynamics and radiation measurements. The adopted flight strategy was aimed at collection of data from the cloud-top region, accompanied by information on fluxes in various levels of the STBL and vertical profiles of thermodynamic and dynamic parameters characterizing the lower atmosphere for the purpose of LES. Of key interest was the cloud top, sampled in the course of porpoise-like flight segments across the EIL, as shown in Fig. 3 of Gerber et al. (2010). In this study we focus on fine-scale measurements collected with 


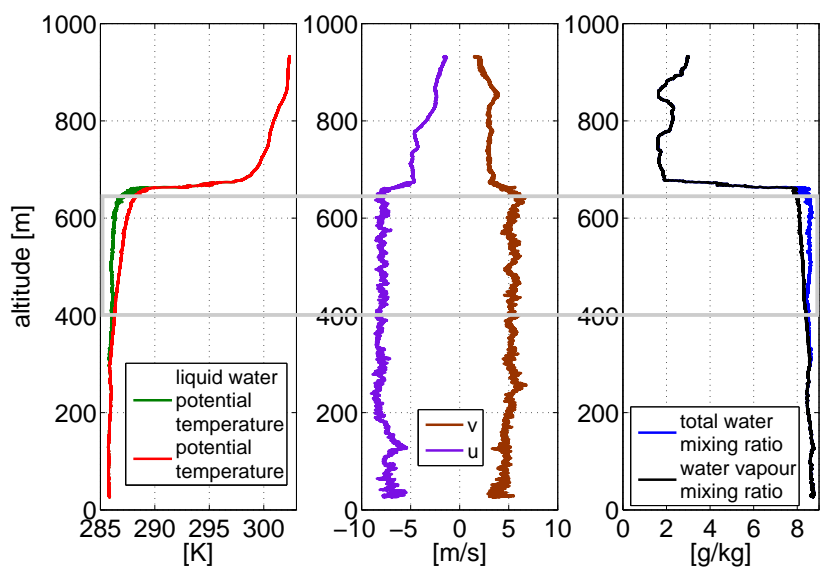

Fig. 2. Vertical profiles of potential temperatures, components of horizontal wind, and mixing ratios characteristic for research flight TO10. Cloud layer marked with a gray box.

the modernized Ultra Fast Thermometer (UFT-M) (Kumala et al., 2013), Particulate Volume Monitor PVM-100 (Gerber et al., 1994), and other fast-response instruments collocated in close proximity around the radome of the aircraft (Fig. 1). The finest-resolution PVM and UFT-M data discussed here are of $1000 \mathrm{~Hz}$ sampling frequency, which corresponds to $\sim 5.5 \mathrm{~cm}$ spatial resolution at $55 \mathrm{~m} \mathrm{~s}^{-1}$ true airspeed (TAS) of the Twin Otter. Other fast-response sensors provided $100 \mathrm{~Hz}$ and $40 \mathrm{~Hz}$ (corresponding to $\sim 55 \mathrm{~cm}$ and $\sim 1.4 \mathrm{~m}$ spatial resolution) measurements of the three components of turbulent velocity fluctuations and absolute humidity, respectively. In some flights the latter was of slightly worse resolution. Microphysical data discussed here were collected by the phase-Doppler interferometer (PDI) (Chuang et al., 2008), located in a pod under the left wing, $\sim 10 \mathrm{~m}$ from the fast sensors. It produces $1 \mathrm{~Hz}(55 \mathrm{~m}$ spatial resolution) drop size distributions. The data are freely available from the POST database maintained by the National Center for Atmospheric Research Earth Observation Laboratory, http: //www.eol.ucar.edu/projects/post/.

Preliminary analysis of entrainment performed by Gerber et al. (2010) distinguished between two different stratocumulus regimes, classified as "classical" (8 cases) and "nonclassical" ( 9 cases). The classical regime is characterized by a shallow and strong inversion capped by a stable, dry FT. Stratocumulus cloud below is characterized by the monotonic increase of cloud liquid water content with height, like in the often-quoted Fig. 4 of the review paper of Stevens (2005) or discussed in Sect. 3 of the recent review of Wood (2012), with "cloud holes" - volumes of reduced liquid water content (LWC) - negatively buoyant and subsiding down into the cloud layer (Gerber et al., 2005, 2010; Malinowski et al., 2011). Non-classical cases show various deviations from such a picture: moist layers above the clouds, fluctuations in LWC profiles within the cloud decks, cloud holes

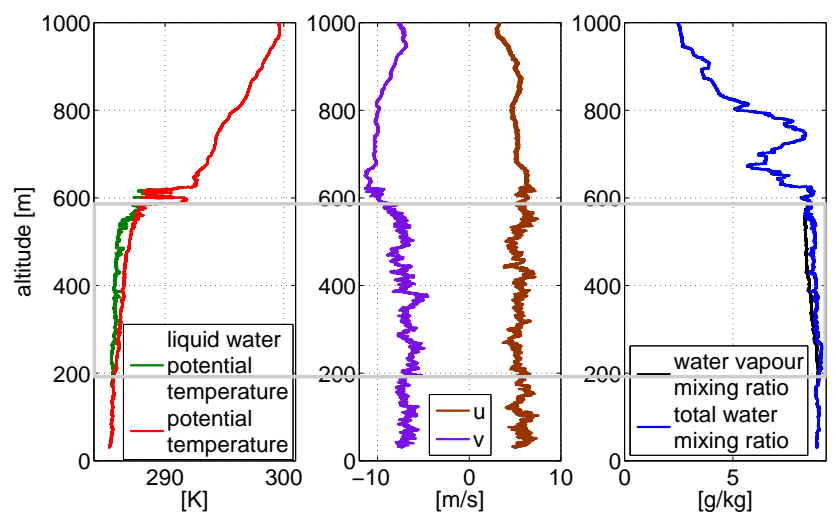

Fig. 3. As in Fig. 2 but for flight TO13.

positively buoyant and/or rising (Gerber et al., 2010, 2013; Malinowski et al., 2011). In the following we analyze details of the EIL structure in two POST cases, TO10 and TO13, which correspond to the classical and non-classical regimes identified above, in order to understand similarities and differences between the behaviors of the cloud top in these two cases and to analyze details of the entrainment process.

\section{Two cases: classical TO10 and non-classical TO13}

\subsection{Atmospheric soundings}

Flight TO10 was performed on 4 August 2008, 17:15-22:15 UTC. It was a daytime flight (local time was UTC -7) in a fairly uniform cloud field (cf. satellite images in POST database). A typical sounding taken in the course of the flight (Fig. 2) shows a sharp liquid water potential temperature $\theta_{1}$ jump $(10 \mathrm{~K})$ in a $\sim 30 \mathrm{~m}$-thick layer above the cloud top, accompanied by a rapid drop of water vapor mixing ratio and a substantial wind shear $\left(\sim 4 \mathrm{~ms}^{-1}\right.$ per $30 \mathrm{~m}$, which gives $0.133 \mathrm{~s}^{-1}$ for each horizontal component of wind velocity).

Meteorological conditions during evening flight TO13 (performed 9 August 2008, 00:58-06:00 UTC) were different from the ones during TO10 (Fig. 3). While the total jump of $\theta_{1}$ between the middle of the mixed layer and the $\sim 1000 \mathrm{~m}$ altitude is comparable to the TO10 case, the sharp inversion above the cloud top has a temperature jump of no more than $\sim 4 \mathrm{~K}$ (in many penetrations this temperature jump was as weak as $\sim 1 \mathrm{~K}$ ). $\theta_{1}$ and total water profiles show dilution of the $\sim 80 \mathrm{~m}$-thick region in the upper part of the cloud. This suggests that this region is dynamically decoupled from the mixed atmospheric boundary layer. The mixing ratio above the cloud top is high. Figure 3 shows fluctuations of humidity and an almost-saturated layer at $\sim 750 \mathrm{~m}$ height. In many penetrations conditions close to saturation were present in a thick layer above the cloud top. The wind jump in the cloud-top region is smaller than in the TO10 case, and the 
shear layer is significantly deeper and penetrates the upper part of the cloud layer. Its bottom correlates with the top of the mixed boundary layer. There is also a substantial variability of the shear layer among the penetrations.

\subsection{Cloud tops}

Figure 4 presents $40 \mathrm{~Hz}$ records of the temperature $(T)$, LWC, pressure corrected altitude and fluctuations of the three components of velocity (the east-west component $u$, the north-south component $v$ and the vertical component $w$ ) during a typical descent into the cloud deck during TO10 flight. A careful inspection of these plots allows the discrimination of regions with substantially different properties, which will be quantified in Sect. 4.

The left part of the plot shows the FT above the inversion, where the temperature and velocity records are smooth, fluctuations are small, and the temperature gradient is moderate. At a certain height the temperature begins to fluctuate rapidly, falling very quickly above cloud top. Velocity variations show the presence of substantial wind shear and turbulence. A temperature jump of $\sim 8 \mathrm{~K}$ is observed along the flight trajectory over a horizontal distance of $\sim 550 \mathrm{~m}$ and a descent of $\sim 12 \mathrm{~m}$. Such temperature drop, wind shear, and turbulence are common features for all porpoises in this flight (see e.g. Fig. 4 region from 67728 s to 67735 s), suggesting the existence of a characteristic turbulent inversion sublayer (TISL) above the cloud top.

Next the aircraft penetrates a first blob of the cloud $($ LWC $>0)$. Subsequent penetrations through a series of cloudy and clear filaments are characterized by remarkable (amplitude $\sim 2 \mathrm{~K}$ ) temperature fluctuations correlated with LWC. In this region horizontal velocities indicate continuing wind shear, slightly weaker than in the TISL. Turbulent velocity fluctuations are increased. Such variations are recorded over a horizontal distance of $\sim 800 \mathrm{~m}$ in an $\sim 18 \mathrm{~m}$-thick layer (on Fig. 4 region from $67735 \mathrm{~s}$ to $67750 \mathrm{~s}$ ). This region is named the cloud-top mixing sublayer (CTMSL), such that the CTMSL together with the TISL form the EIL. In fact we extend here a standard notion of the EIL as a sublayer of the capping inversion above the cloud top moistened by former mixing events (see e.g. Gerber et al., 2005). This will be elaborated more in the following Sect. 4 of the paper.

Finally, as the temperature ceases to fluctuate significantly, the character of the records changes. There are remarkable fluctuations of LWC, but the value at $40 \mathrm{~Hz}(\sim 1.4 \mathrm{~m}$ spatial resolution) remains everywhere above 0 . Temperature fluctuations become small, typically $0.2 \mathrm{~K}$, in contrast to those in the CTMSL that exceed $2 \mathrm{~K}$. Velocity fluctuations are still large, especially for the vertical component. This region is called the cloud-top layer (CTL).

In Fig. 5, $40 \mathrm{~Hz}$ time series of $T$, LWC, altitude, and velocity fluctuations in a typical penetration of the cloud top during flight TO13 are presented. In contrast to the TO10 case, the beginning of the temperature inversion and increased small-scale fluctuations discriminating the FT and TISL are less distinct. The beginning of the CTMSL is again diagnosed with a first blob of cloudy air. There are increased velocity fluctuations associated with this blob and successive cloud volumes. Except for the first cloudy filaments, the LWC in the CTMSL only slowly approaches the maximum LWC in the CTL below. This suggests that cloud filaments in the CTMSL do not contain adiabatic parcels originating close to the surface and transported there across the whole BL by convective updrafts, which again suggests dynamical decoupling. Humidity in both cloud and clear-air filaments approaches the saturation value. In contrast to the TO10 case, fluctuations of $T$, LWC, and all velocity components continue, with little change to mark the border between the CTMSL and CTL.

\subsection{Fine-scale structures}

In order to better illustrate differences between the layers of the TO10 cloud top, typical fine $(1000 \mathrm{~Hz}, \sim 5.5 \mathrm{~cm}$ resolution) structures of LWC and $T$ fields are presented in Fig. 6. The upper panel presents the temperature record on $\mathrm{a} \sim 200 \mathrm{~m}$-long segment of flight inside the TISL. Very narrow $(\sim 20 \mathrm{~cm})$ filaments of temperature differences exceeding $1 \mathrm{~K}$ indicate active turbulent mixing. The middle panel displays records of $T$ and LWC in the CTMSL - penetrations through consecutive filaments of undiluted (maximum LWC on the porpoise) cloudy blobs; diluted, partially evaporated cloudy filaments and clear-air parcels (cf. Figs. 6-13 in Haman et al., 2007). The amplitude of temperature fluctuations within these clear-air parcels is comparable to that in the TISL. Inside the undiluted and diluted cloudy filaments, the amplitude of temperature fluctuations is an order of magnitude smaller and temperature variations are not correlated with those of LWC. Finally, in the lowest panel, records from inside the CTL on a segment with cloud holes present are shown for comparison. The amplitude of temperature fluctuations is $\sim 0.1 \mathrm{~K}$ like in cloudy blobs in the CTMSL, and $T$ and LWC fluctuations are usually correlated with few exceptions.

The fine-scale structure of successive layers of TO13 stratocumulus top is shown in Fig. 7. Again, large fluctuations of $T$ are observed in the TISL, indicating turbulent mixing. The amplitude of these fluctuations is smaller than in TO10 in accordance with the smaller temperature jump across the inversion. In the CTMSL, diluted cloudy blobs (reduced LWC) prevail and there are not so many clear-air filaments as in TO10. This is in agreement with the higher humidity of the FT and TISL, which prevents the mixed cloud parcels from rapid evaporation. Regions of reduced LWC are broader and the borders are less sharp. $T$ and LWC records in the CTL are correlated, again with few exceptions. 

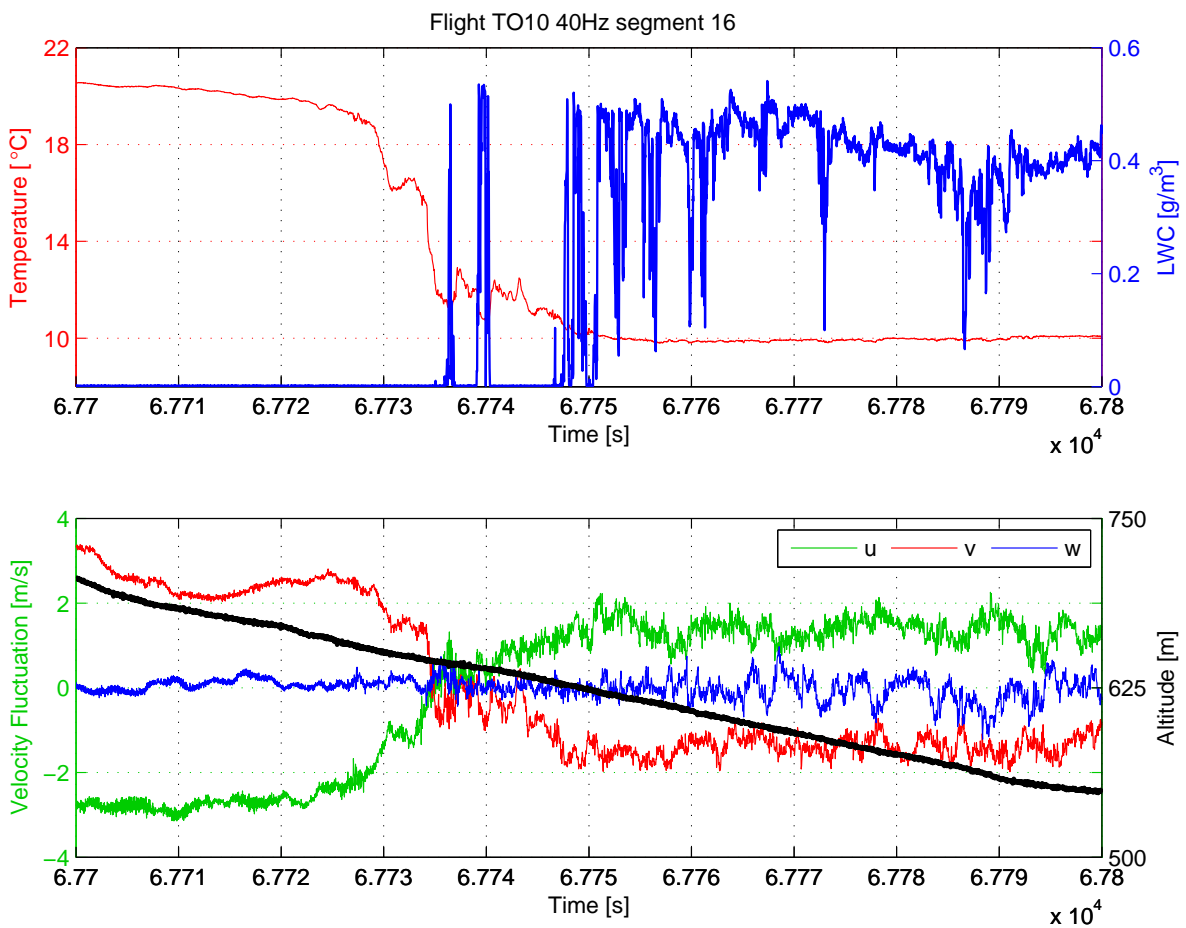

Fig. 4. Temperature $T$, liquid water content LWC, and velocity fluctuations (mean values subtracted) in the course of a descent into the stratocumulus cloud deck, illustrated by the altitude (black line), during flight TO10.
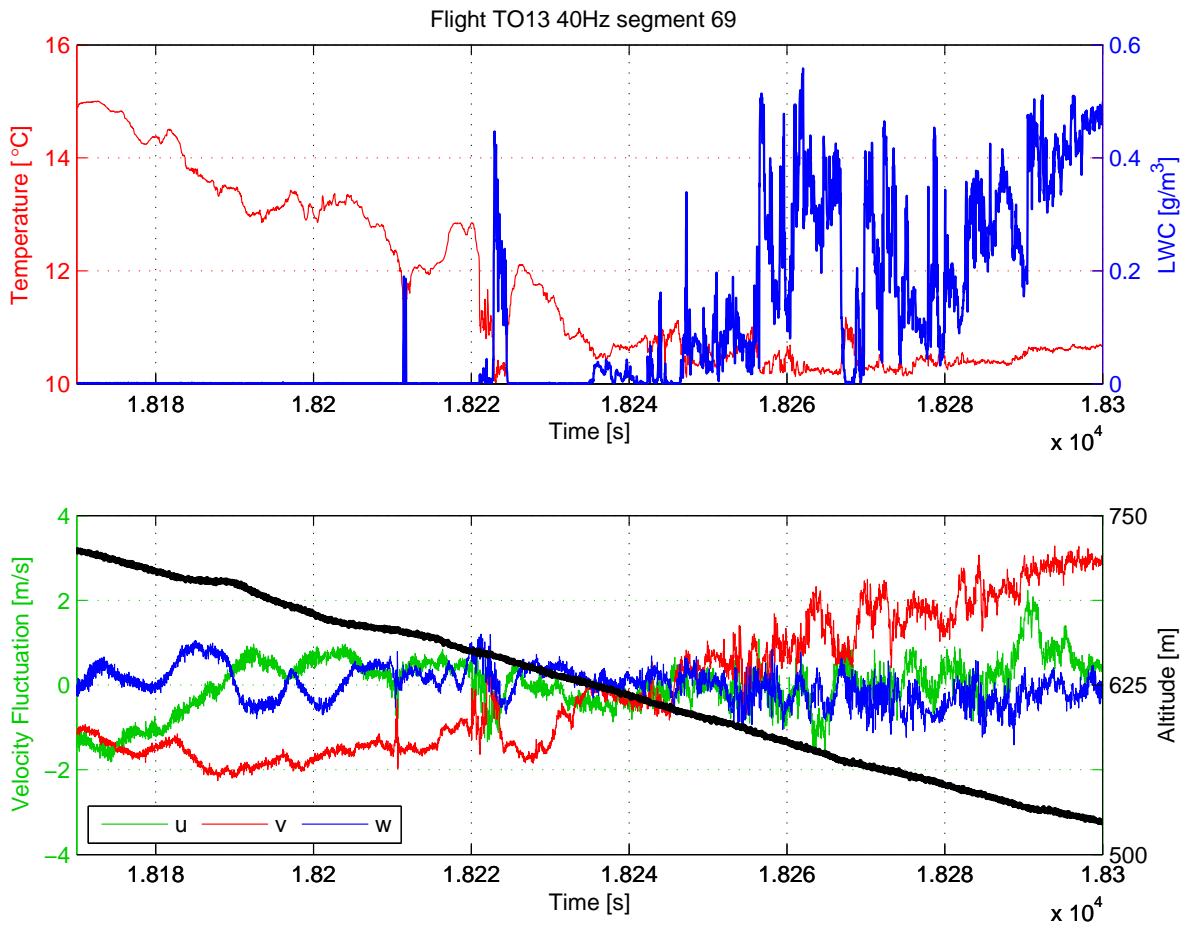

Fig. 5. As in Fig. 4 but for flight TO13. 

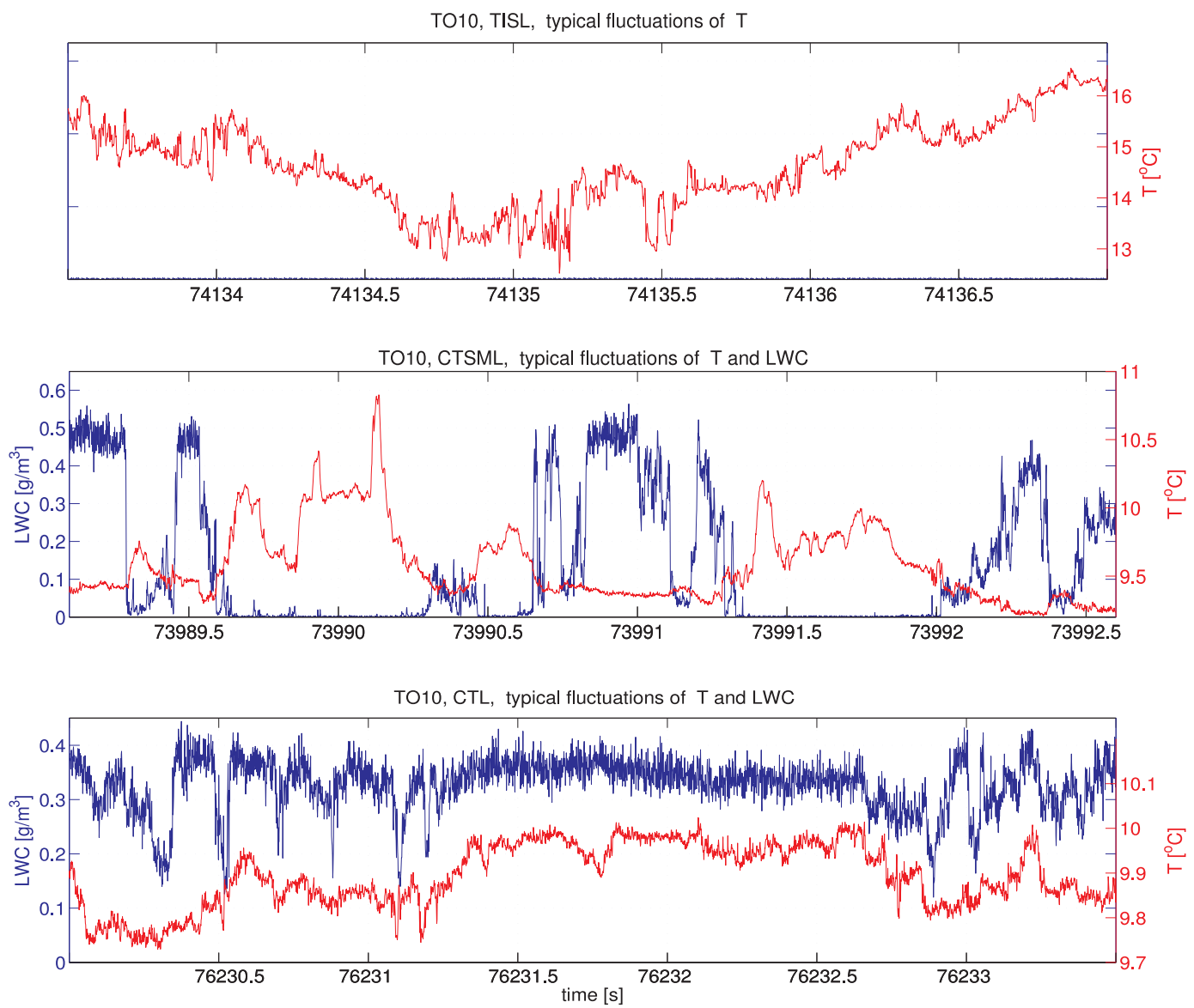

Fig. 6. Typical high-resolution $(\sim 5.5 \mathrm{~cm})$ records of temperature and LWC fluctuations in TISL (upper panel), CTMSL (middle panel) and CTL (bottom panel) from flight TO10.

\subsection{LWC profiles}

Let us analyze vertical profiles of LWC across the CTMSL and the CTL. Figure 8 shows LWC averaged over a $1.4 \mathrm{~m}$ long distance $(40 \mathrm{~Hz}$ data), as a function of height for 12 successive penetrations of cloud top in the course of the TO10 flight. Typically, the maximum of the LWC envelope increases linearly with height, suggesting the presence of parcels lifted (almost) adiabatically from the cloud base (cf. Pawlowska et al., 2000) or even from the surface. Parcels with reduced LWC most often appear in the CTMSL, while in the CTL a depletion of LWC is less common and indicates the presence of cloud holes (Gerber et al., 2005), i.e., parcels of negative buoyancy, formed in the course of mixing and evaporative cooling at the cloud top, slowly descending across the cloud deck as shown in Fig. 12 of Kurowski et al. (2009).

In Fig. 9 twelve typical vertical profiles of LWC collected in the course of flight TO13 are presented in a similar manner to Fig. 8. The difference between TO13 and TO10 is striking. In TO13 the maximum of the LWC envelope in the cloud-top region decreases or is constant with height. Additionally, sev- eral panels in Fig. 9 suggest that the layer with the decreasing maximum LWC envelope tops a layer with the typical (for stratocumulus clouds) linear increase of the maximum LWC envelope with altitude.

It is worth mentioning that such a profile of LWC in stratocumulus top is not unique. It resembles, e.g., the RF08B case of FIRE I campaign - cf. Fig. 6 in De Roode and Wang (2007).

\subsection{Microphysics}

Figure 10 shows in-cloud vertical profiles of median cloud microphysical properties averaged for the entire flight TO10. Observations are from the PDI and are binned by altitude for each individual slant ascent or descent relative to the cloud top for that ascent or descent profile using a threshold of $0.05 \mathrm{~g} \mathrm{~kg}^{-1}$. On this day, the median (or 50th percentile) drop diameter generally increases slowly with altitude, ranging from $15 \mu \mathrm{m}$ at an altitude of $100 \mathrm{~m}$ below cloud top to nearly $17 \mu \mathrm{m}$ right at cloud top. This same slow increase in drop size is also found for other percentiles of the drop distribution. The breadth of the number size distribution thus is generally 

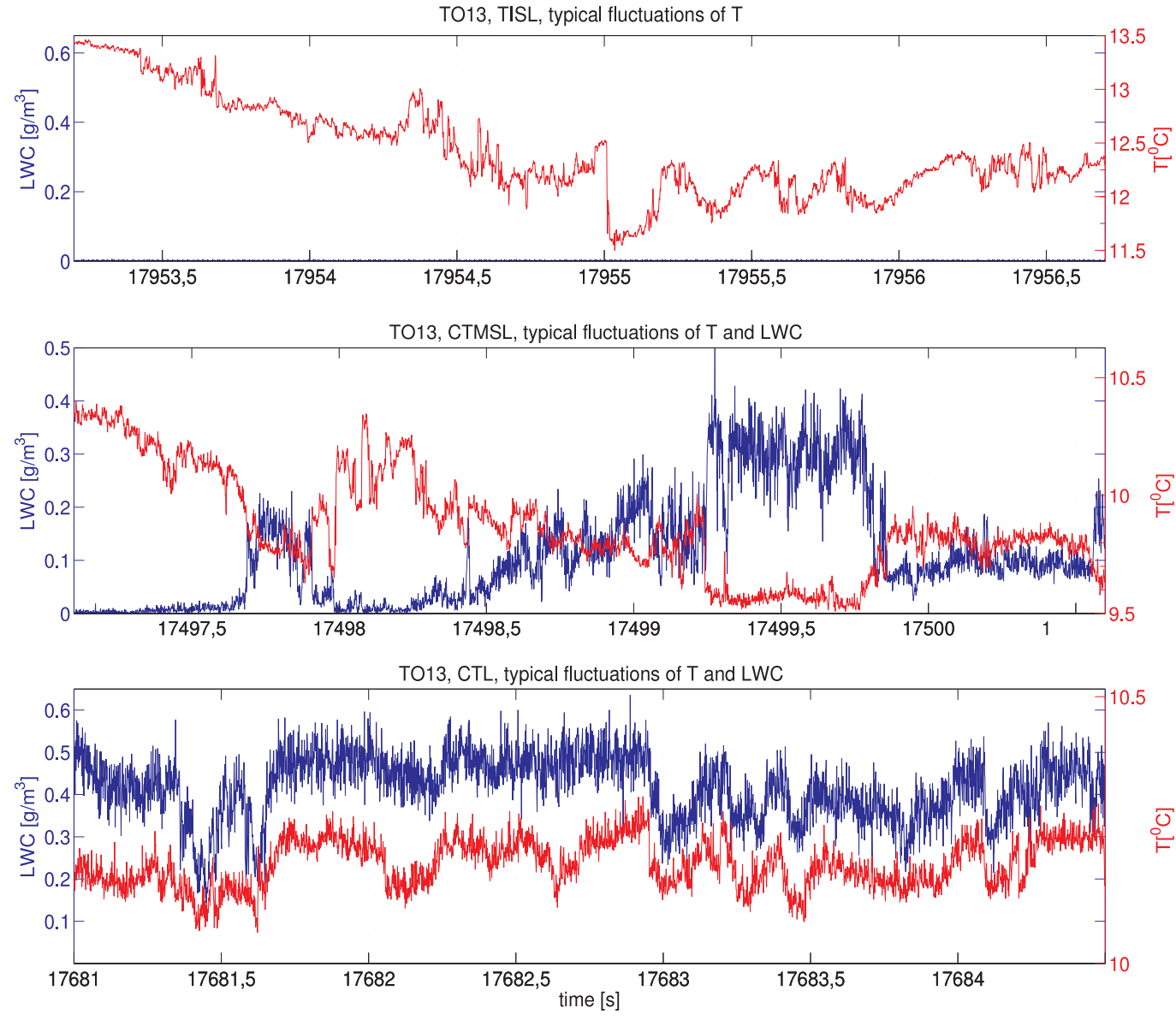

Fig. 7. As in Fig. 6 but for flight TO13.

quite similar in this portion of the cloud. The drop number concentration is reasonably constant with altitude (between 100 and $120 \mathrm{~m} \mathrm{~g}^{-1}$ ) given that the average standard deviation in drop concentration for each altitude is $11 \mathrm{mg}^{-1}$. Overall, the microphysical observations indicate a fairly well-mixed cloud whose properties are dominated mainly by condensational growth and do not exhibit any strong signs of entrainment effects. It is possible that the decrease in drop number concentration in the top $10 \mathrm{~m}$ of the cloud indicates a modest amount of inhomogeneous mixing, but, as mentioned earlier, the effect is within the range of uncertainty.

Figure 11 shows averaged cloud microphysical property profiles for flight TO13. On this day the drop diameters are larger than in TO10 by almost $10 \mu \mathrm{m}$, with median drop sizes around 24 to $26 \mu \mathrm{m}$. The median drop diameter appears to be quite constant with altitude in the top $60 \mathrm{~m}$ of the cloud (between -60 and $0 \mathrm{~m}$ ) rather than slowly increasing as in TO10. The drop size distribution broadens towards smaller sizes as altitude increases in this same region, as evidenced by the decreases in the 10th- and 25th-percentile drop diameters. Drop number concentration generally decreases with altitude, from around $50 \mathrm{mg}^{-1}$ at $120 \mathrm{~m}$ below cloud top down to $20 \mathrm{mg}^{-1}$ right at cloud top. These profiles are consistent with a poorly-mixed or decoupled cloud-top region. Entrainment and mixing appear to both decrease drop concentration, by dilution and potentially by complete evaporation of drops, as well as cause some drops to partially shrink in size. High humidity of entrained air suggests that dilution will affect the number concentration to a much greater degree than total evaporation, also consistent with the observations.

One contributor to the median drop size remaining constant near cloud top in response to entrainment may be that collisional growth is also active in this cloud. The size distribution at the large diameter side extends to fairly large sizes (90th-percentile diameter around $32 \mu \mathrm{m}$ ), which is most likely caused by collisional growth. Intermittent drizzle is also much stronger on this day as compared with TO10, consistent with the larger drop sizes.

\section{Data analysis and discussion}

The previous section documents substantial differences between the classical TO10 and non-classical TO13 
TO10, LWC profiles
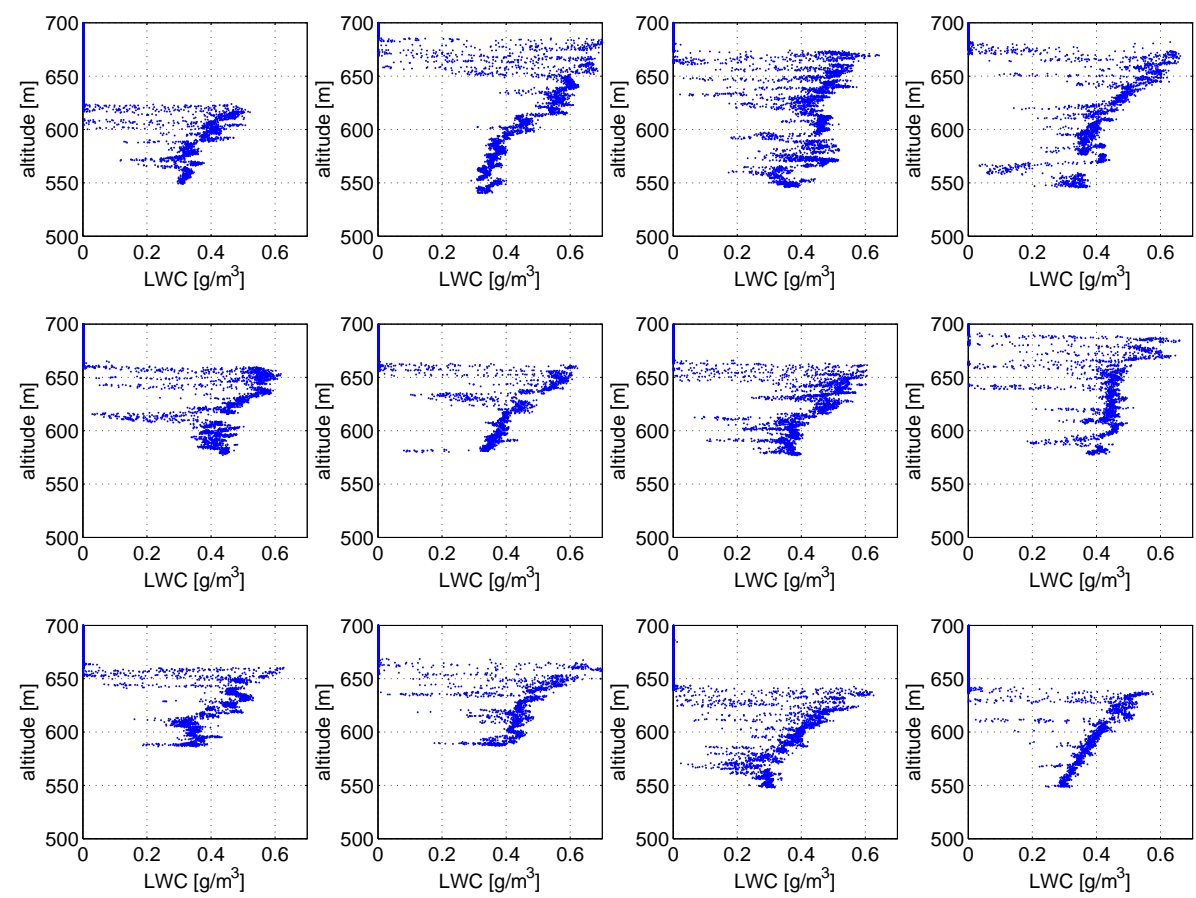

Fig. 8. Typical profiles of LWC collected on porpoises in flight TO10. Each point corresponds to a $1.4 \mathrm{~m}$ average ( $40 \mathrm{~Hz}$ data). Four consecutive profiles are shown in each row. Successive rows are from different flight legs in order to illustrate variability of LWC for the whole flight.

TO13, LWC profiles
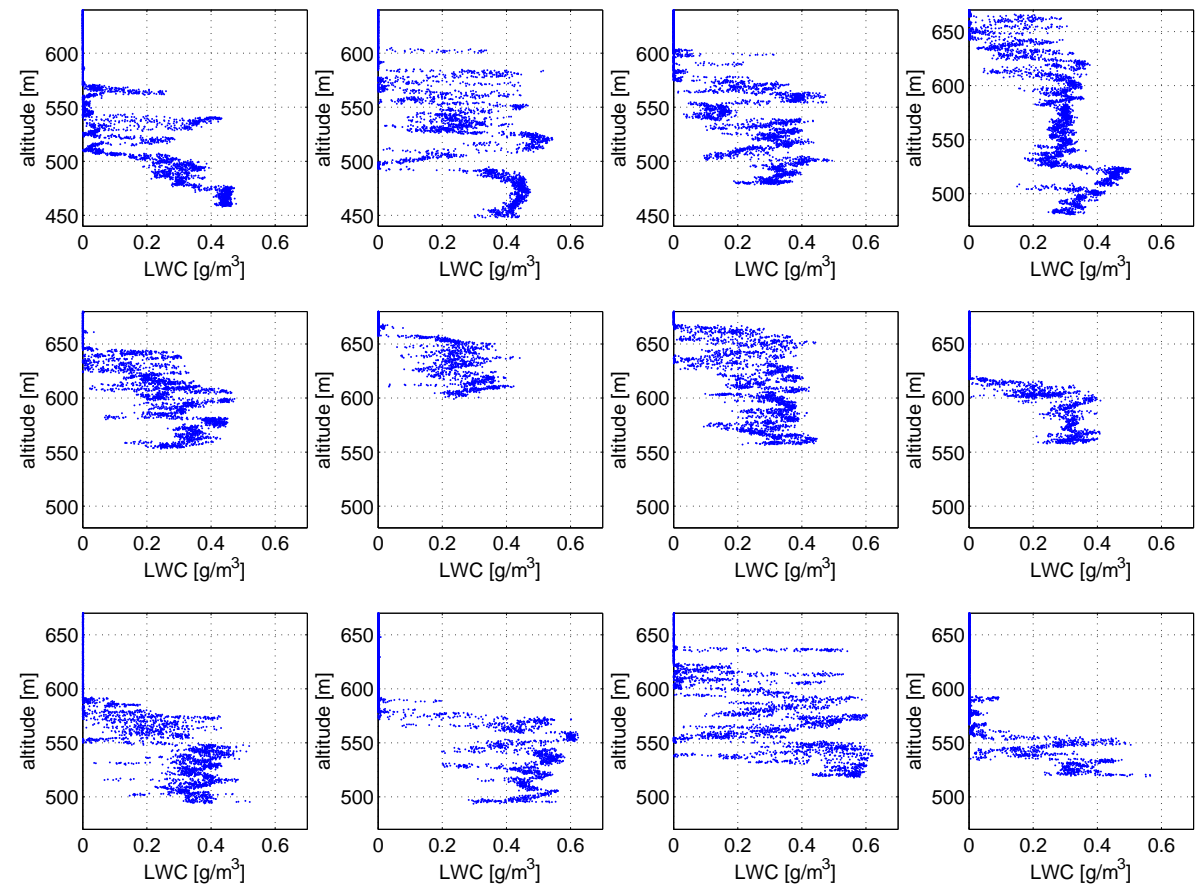

Fig. 9. As in Fig. 8 but for flight TO13. 


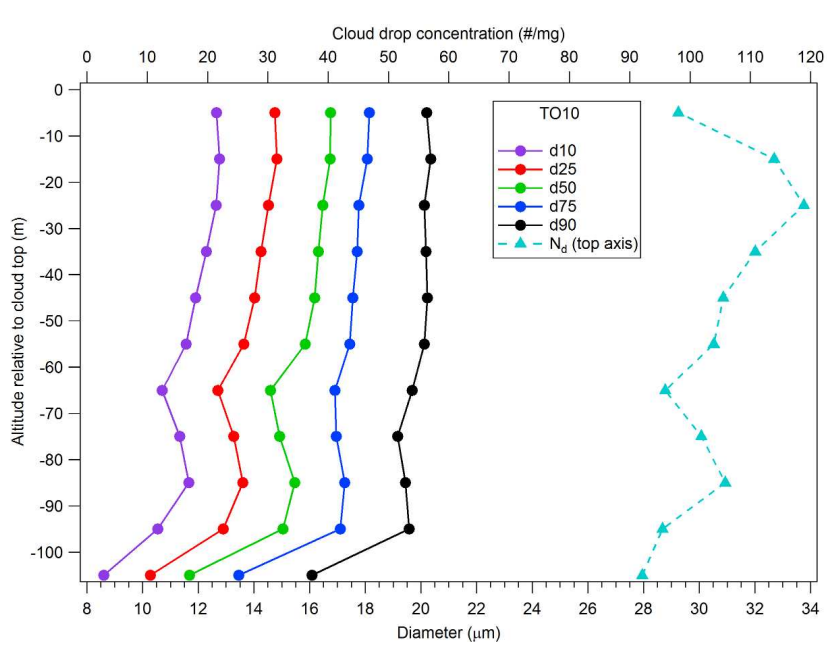

Fig. 10. Vertical profiles of droplet number concentration (triangles, blue, upper axis) and percentiles of droplet size distribution (circles) as a function of altitude relative to cloud top (binned to 10 intervals). Measurements from the phase-Doppler interferometer during TO10.

stratocumulus cases. These differences in thermodynamical, microphysical and dynamical properties of stratocumulus tops were reflected in the visual appearance of the clouds. Observers onboard the aircraft reported "classic stratocumulus layer" in the course of TO10, in contrast to "cloud tops looking like moguls," i.e., the bumps on a ski slope, in TO13. Clearly, the nature of differences requires deeper insight into the data.

\subsection{Layer division}

Detailed analysis of all porpoises in data from the two flights showed that in the majority of recorded cases a division into similar cloud-top sublayers is possible. Testing various criteria led to a quantitative definition of the division. In addition to LWC, the criteria take into account the gradient of liquid water potential temperature, $\Delta \theta_{1} / \Delta z$; the turbulent kinetic energy, TKE; and the square of the horizontal wind shear, $(\Delta u / \Delta z)^{2}+(\Delta v / \Delta z)^{2}$, obtained as the sum of squares of the horizontal velocity deviations. Calculations of TKE and the horizontal wind shear use a moving average of 300 points from the $40 \mathrm{~Hz}$ data. $\Delta \theta_{\mathrm{l}} / \Delta z$ is calculated from a linear fit of the liquid water potential temperature over the same interval. The averaging length corresponds to a distance of $\sim 450 \mathrm{~m}$, chosen to average across a few large turbulent eddies, with a typical size of $\sim 100 \mathrm{~m}$. On the other hand, given the $1.5 \mathrm{~m} \mathrm{~s}^{-1}$ ascent/descent rate, such averaging allows distinguishing between layers of thickness of $\sim 10 \mathrm{~m}$. All three properties are illustrated for a segment from each flight in Figs. 12 and 13.

In these figures the sublayers are delineated by three vertical black lines. From left to right, the first line shows the separation between the FT and TISL, which is identified

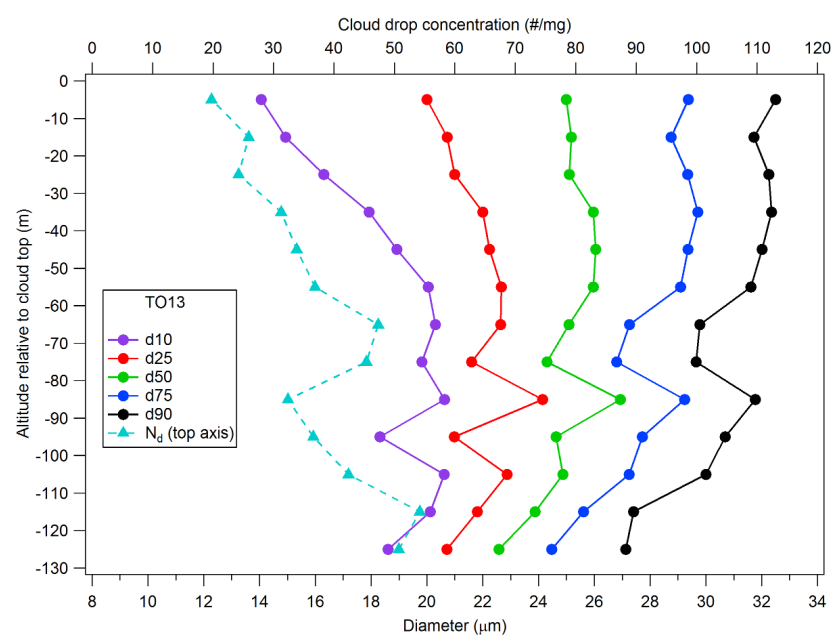

Fig. 11. As in Fig. 10 but for flight TO13.

as the top of capping inversion, i.e., highest point where $\Delta \theta_{1} / \Delta z$ exceeds $0.2 \mathrm{Km}^{-1}$ and simultaneously TKE exceeds $0.1 \mathrm{~m}^{2} \mathrm{~s}^{-2}$. Next the division between the TISL and CTMSL corresponds to the uppermost point where LWC exceeds $0.05 \mathrm{~g} \mathrm{~m}^{-3}$, as shown for the same flight segments in Figs. 4 and 5. The final division between the CTMSL and CTL is determined by the point where the square of the horizontal wind shear reaches $90 \%$ of maximum.

For the descending segment of flight TO10 shown in Fig. 12, the division between the FT and TISL occurs at

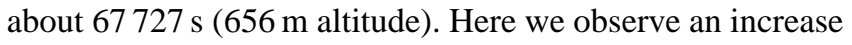
of rapid temperature fluctuations superimposed on a negative trend. The turbulent kinetic energy remains high throughout the TISL. Next comes the first indication of the CTMSL at $67736 \mathrm{~s}$ (644 m altitude), where the temperature is becoming more stable and turbulent kinetic energy is decreasing. This is followed by the CTL at $67748 \mathrm{~s}$ ( $626 \mathrm{~m}$ altitude). From this point LWC stays above zero, while the temperature, turbulent kinetic energy, and horizontal wind stabilize.

As noted, the layers are less distinct in flight TO13 than in TO10. Divisions using these criteria were possible for about half of all segments in this flight. For the segment shown in Fig. 13, the division between the FT and TISL occurs at about $18184 \mathrm{~s}$ (730 m altitude) and coincides with the occurrence of very small, rapid $T$ fluctuations. The CTMSL begins at $18211 \mathrm{~s}$ (663 m altitude) with the first distinct cloud blob and continues for much of the penetration. Both the TISL and CTMSL show significant variation of $\Delta \theta_{1} / \Delta z$, in contrast to the distinct maximum in the TISL for flight TO10. Finally at $18291 \mathrm{~s} \mathrm{(536} \mathrm{m}$ altitude) the CTL is reached and the horizontal wind plateaus. The layers are notably thicker in this case, with a TISL thickness of $67 \mathrm{~m}$ and CTMSL thickness of $127 \mathrm{~m}$ compared to $12 \mathrm{~m}$ and $18 \mathrm{~m}$, respectively, for flight TO10. 

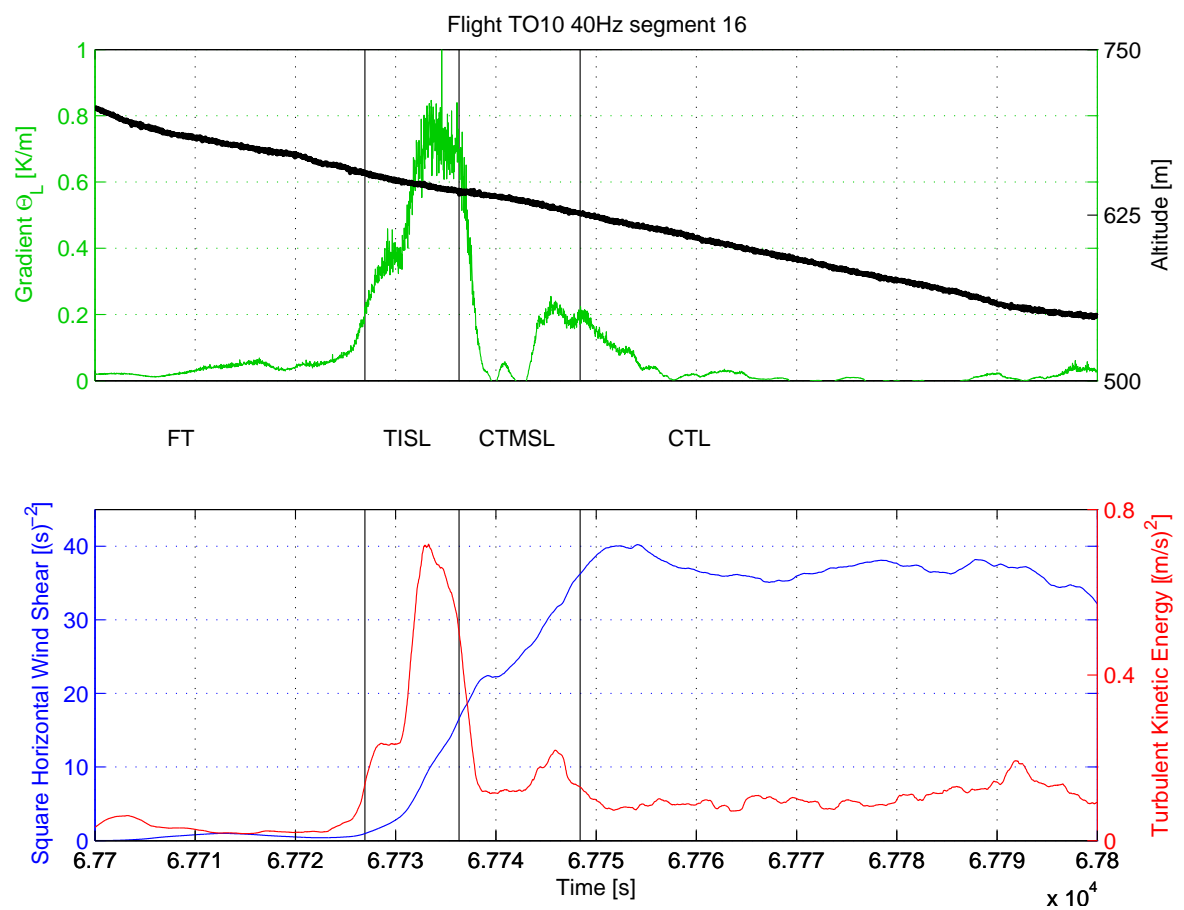

Fig. 12. Gradient of the liquid water potential temperature, horizontal wind, and turbulent kinetic energy for the same descending segment of flight TO10 shown in Fig. 3. Three black vertical lines mark borders between the free troposphere, the inversion, the cloud mixing layer and the cloud top.
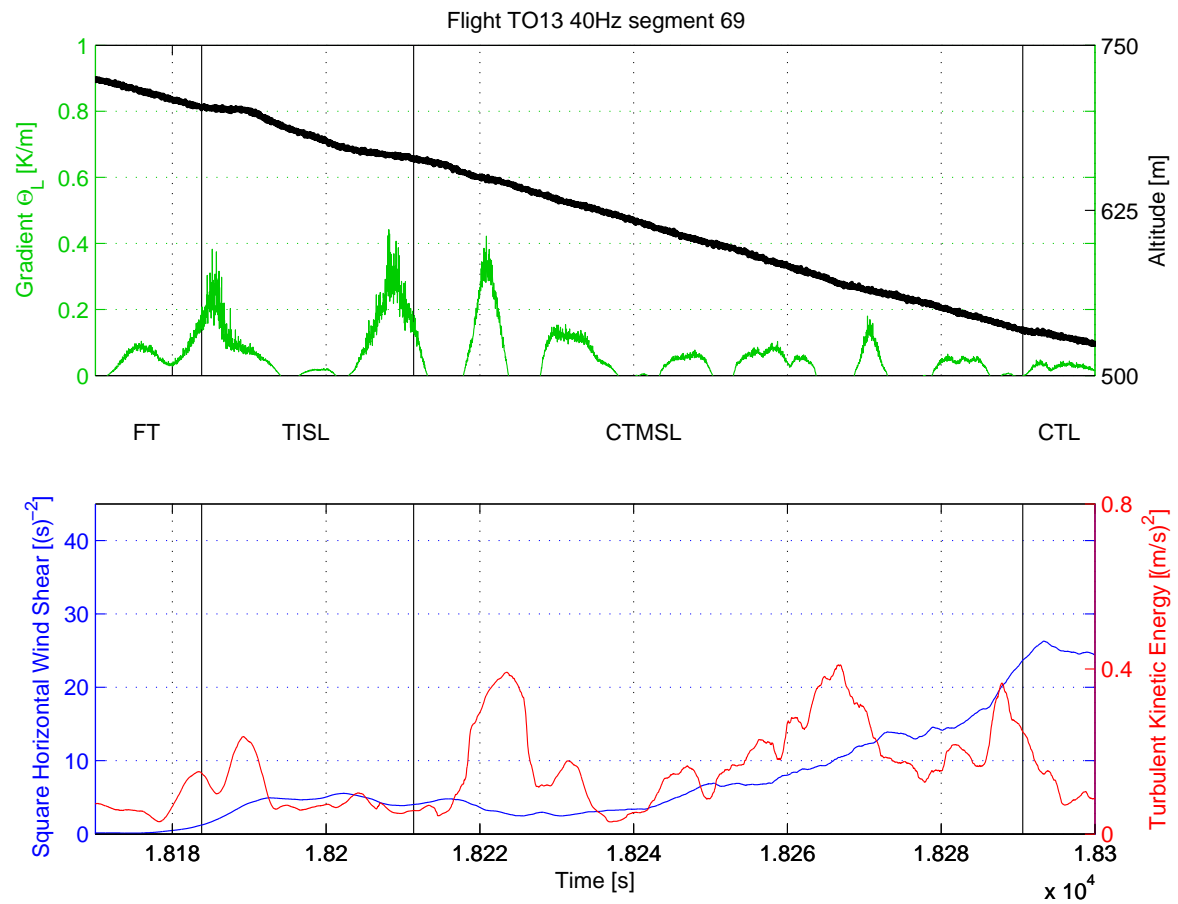

Fig. 13. As in Fig. 12 but for flight TO13. The flight segment corresponds to Fig. 8. 


\subsection{Richardson number}

Using the divisions just described, the bulk Richardson number is estimated for each layer according to the following formula:

$$
R i=\frac{\frac{g}{\theta}\left(\frac{\Delta \theta}{\Delta z}\right)}{\left(\frac{\Delta u}{\Delta z}\right)^{2}+\left(\frac{\Delta v}{\Delta z}\right)^{2}},
$$

where $g$ is the acceleration due to gravity, and $\Delta \theta, \Delta u$ and $\Delta v$ are the jumps of potential temperature and horizontal velocity components across $\Delta z$ - the thickness of each of the layers (TISL, CTMSL, EIL) and the vertical distance between the nearest layer division and altitude of turnover for the FT and CTL. Note that this is a crude estimate of $R i$, subject to uncertainties due to the measurements along an inclined trajectory, deflections of the cloud top from planeparallel structure and possible non-stationarity of cloud processes. Nevertheless, we believe that statistics of $R i$ estimates from a vast number of cloud-top penetrations provide us at least qualitative insight into the properties of turbulence in the vicinity of cloud top.

Figure 14 shows histograms of $R i$ values estimated on porpoises of flight TO10 in the consecutive layers: the lower $\sim 50 \mathrm{~m}$ of the FT (top left), TISL (top right), CTMSL (middle left), CTL (middle right) and EIL (combination of TISL and CTMSL, bottom). The sampled thickness of the FT and CTL varies across segments due to differences in the turnaround between ascending and descending segments, or vice versa, relative to the cloud. This can affect the Richardson number observed across those partial layers. Flight segments where the calculated Richardson number fell outside the range $[-2,8]$, or where the layers were not identified, are not included in the histograms.

Recalling many studies (see, e.g., recent discussions in Galperin et al., 2007; Grachev et al., 2012), values of $R i>1$ suggest stably stratified, non-turbulent fluid. While $R i_{\mathrm{C}}=$ 0.25 is usually considered a critical value, in the range of $0.25<R i<1$ turbulence is often observed. Positive values $0<R i<0.25$ correspond to fully turbulent, stably stratified fluid, while $R i<0$ indicate statically unstable fluid. Keeping the above in mind, the two upper panels of Fig. 14 indicate that the FT is stably stratified and mostly non-turbulent. In contrast the TISL, characterized by increased static stability, is marginally turbulent: estimates of $R i$ from all penetrations peak narrowly in the three highlighted bins centered at 0.25 , 0.50 and 0.75. $R i$ histograms from the CTMSL and CTL require more discussion. First, the median values of $R i$ in the CTMSL and CTL indicate turbulence. There are also signatures of $R i<0.25$ in both layers and $R i<0$ in the CTL. Second, from the vertical sounding and the definition of $R i$ it follows that $R i$ estimates in the CTL and in some penetrations of the CTMSL come from small differences in horizontal wind and $\theta$. Thus, they are associated with large errors resulting from the division of two small numbers. This can be verified in Fig. 12, where the gradient of $\theta_{1}$ (not very different from the gradient of $\theta$ ) and the horizontal wind across these layers had very small values. Similar reasoning explains the observed variability of $R i$ estimates in the FT: the wind shear in this layer is small, especially in the case of shallow penetration into the FT in the course of a porpoise.

The last histogram of $R i$ in Fig. 14 allows the characterization of the whole EIL. This estimate is more reliable, since the division between the TISL and CTMSL in each porpoise is affected by random error due to inherent variability in the height of the top-most cloud blob. It is also the closest to the canonical interpretation of $R i$, i.e., the ratio of potential to kinetic energies across the whole depth of the shear layer. Clearly, the values of $R i$ indicate that the EIL is marginally turbulent.

Figure 15 presents histograms of $R i$ for the TO13 case. In general, the distributions are quite similar to those from TO10. The statistics are limited since only about half the flight segments had well-identified layers, as discussed in the previous section. Weaker temperature gradients across the TISL result in the larger uncertainty of $R i$ determination. However, a vast majority of the cases in both the TISL and CTMSL fall into three bins centered at 0.25, 0.50 and 0.75, indicating marginally turbulent layers. This is also true for the whole EIL. Similar experimental values of $R i$ at Sc top are reported by Lenschow et al. (2000) and Katzwinkel et al. (2012). Histograms in Fig. 14e and Fig. 15e closely resemble that in Fig. 7 of Wang et al. (2012) obtained from LES simulations.

\subsection{A conceptual model of Sc top}

A surprisingly consistent picture of the cloud-top region dynamics emerges from the analysis of the two very different cases. The free troposphere above the inversion is statically and dynamically stable. Values of $R i>1$ suggest no turbulence, which is consistent with the appearance of the velocity and temperature records. The layers below (TISL, CTMSL and their combination - EIL) are turbulent, with $R i \approx R i_{\mathrm{C}}$ indicating closeness to the margin of stability. Frequent sharp fluctuations of temperature, LWC and all velocity components demonstrate the presence of intensive mixing. Despite the maximum static stability across the TISL, the inversion is turbulent and the border between the non-turbulent FT and the turbulent TISL is sharp since no gradual variation of small-scale velocity fluctuations with height is observed. The location of this border coincides with the upper limit of the wind shear layer. This is also in agreement with a generic concept of entrainment as "the mean inflow across the edge of a turbulent flow" (see the review paper by Turner, 1986).

How can such a consistent picture of the EIL emerge, despite different temperature and velocity jumps, visual appearances of clouds and thermodynamic properties of cloud tops? 

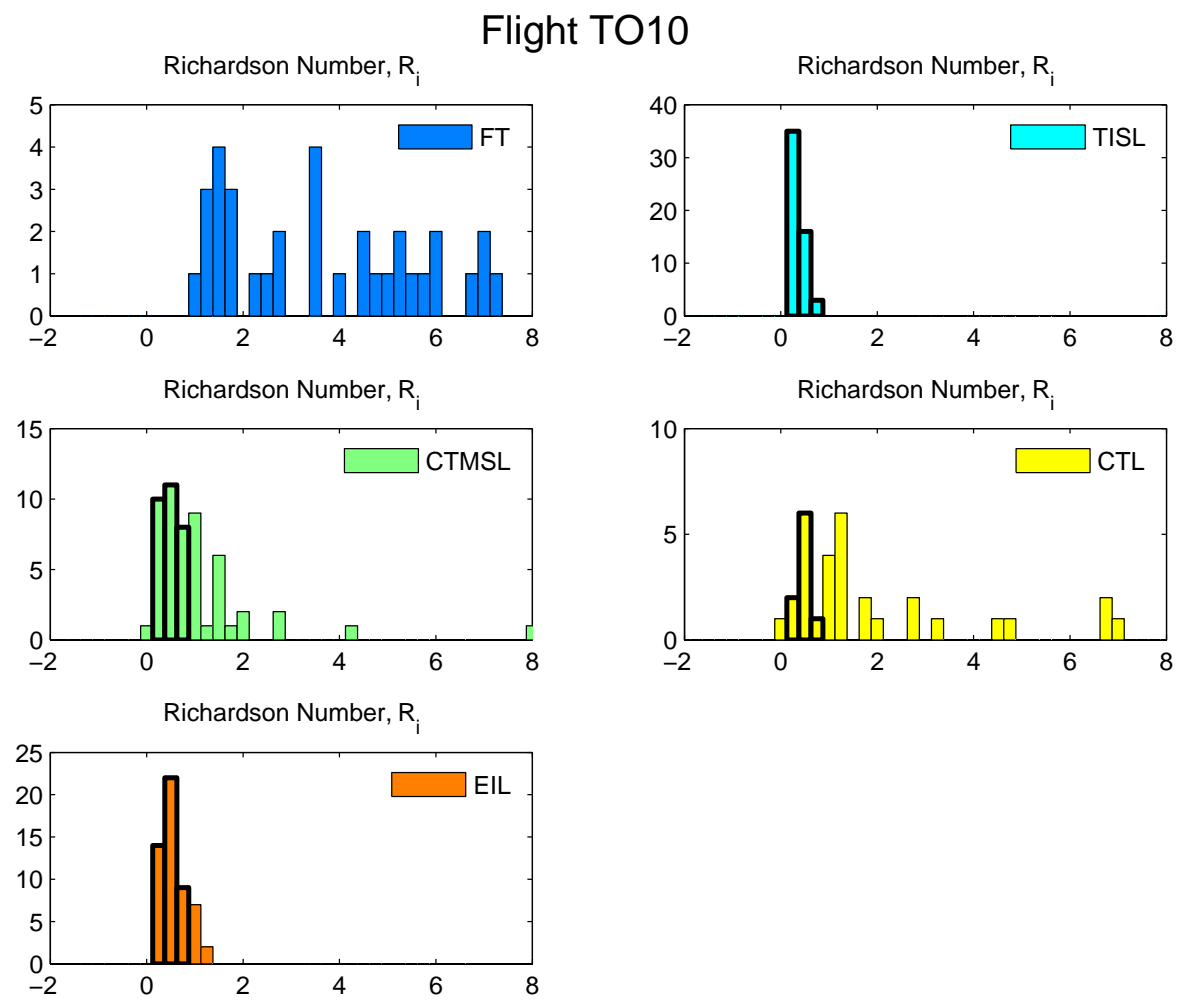

Fig. 14. Distribution of observed Richardson number in each layer for different porpoises in flight TO10. The width of each bin is 0.25 . The heavy black lines highlight the critical bins centered on $R i=[0.25,0.5,0.75]$.

Consider the formula for $R i$, rewritten as

$R i=\left(\frac{g}{\theta}\right) \frac{\Delta \theta}{\Delta u^{2}+\Delta v^{2}} \Delta z$.

Remember that forcings responsible for temperature and velocity jumps across the EIL (TISL), $\Delta \theta, \Delta u$, and $\Delta v$, assuming convectively well-mixed STBL, are radiative cooling at the cloud top, large-scale subsidence, advection and horizontal pressure gradient. The only local parameter is layer thickness, $\Delta z$. Observed $R i \approx R i_{\mathrm{C}}$ across the EIL (TISL) suggests a dynamical adaptation of $\Delta z$ to forcings. This suggestion, formulated in a stratocumulus context by Katzwinkel et al. (2012) (see Fig. 5 therein and accompanying discussion), is well documented in oceanic statically stable shear layers (see Smyth and Moum, 2000, cf. Figs. 11 and 12 therein or the review paper by Peltier and Caufield, 2003). If confirmed, this finding paves the road to entrainment/mixing parametrization based on properties of turbulence in the TISL along the reasoning of Pham and Sarkar (2010).

Now the second problem needs explanation: why, despite such strong similarities in dynamics, are the cloud tops in TO10 and TO13 so different? Analysis of mixing diagrams indicates that thermodynamic properties of the CTL and FT in TO10 allow cloud-top entrainment instability (CTEI): uniform mixtures of air from the cloud top and above the EIL of fraction $\chi<0.12$ of clear air are negatively buoyant, and only those of fraction $\chi<0.11$ are saturated after mixing. Independent analyses of buoyancy reversal and mixing fraction performed by Gerber et al. (2013) confirm CTEI in TO10. In such case mixed cloudy parcels of reduced LWC (and some clear parcels close to saturation) are quickly removed from the CTMSL due to the action of negative buoyancy. Thus, cloudy parcels in the CTMSL are almost unmixed, with relatively narrow droplet spectra and high LWC. Mixed clear-air parcels, of increased temperature and humidity, contribute to the thickness of the TISL and undergo consecutive mixing events in turbulent inversion.

In contrast, the conditions during TO13 are CTEI prohibiting. Mixing of air from the CTL with humid, only slightly warmer air from the FT cannot reverse buoyancy. Mixtures of as high a fraction of clear air as $\chi<0.7$ are still cloudy (with reduced LWC and droplet concentration) and positively buoyant (again in agreement with Gerber et al., 2013). The majority of mixed parcels maintaining cloud water remain close to the level where mixing occurred, undergoing secondary mixing events. Inhomogeneous mixing is more likely in the humid environment (see, e.g., analysis of characteristic times of mixing and evaporation in Andrejczuk et al., 2009) and leads to the reduced sizes of small droplets, while the long residence time of cloudy parcels in the highly turbulent CTMSL may lead to formation of larger droplets due to collision-coalescence processes. 
Flight TO13
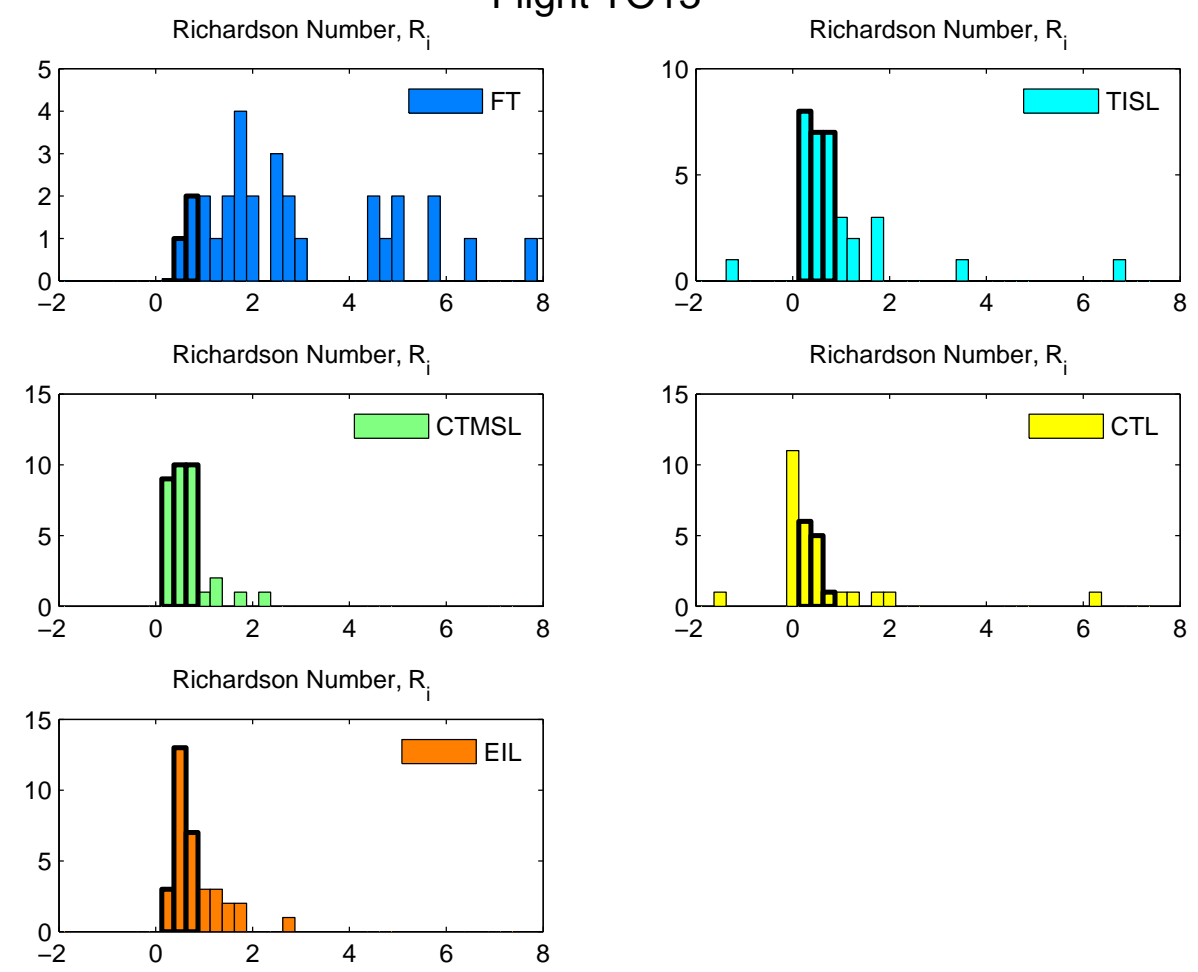

Fig. 15. As in Fig. 14 but for flight TO13.

Taking into account the above analysis, the structure and phenomenology of the stratocumulus top can be summarized graphically in Fig. 16. The STBL is capped by the nonturbulent free troposphere. Within the STBL air is well mixed due to the action of large convective eddies spanning the whole STBL depth (indicated in the illustration as double violet-grey arrows). The entrainment interface layer is turbulent (red spirals with arrows). Through the self-adapting thickness of the EIL, turbulence is kept at a level close to dynamic equilibrium, resulting from production by wind shear (straight brown arrows) and damping by strong static stability (green profile of $\theta_{1}$ ).

The effects of turbulent mixing depend on the thermodynamical properties of the FT and the CTL. In a CTEIpermitting situation those mixed and homogenized parcels which are cloudy or close to saturation are removed from the CTMSL by negative buoyancy (white arrows in the left panel). The remaining homogenized clear-air parcels are subject to secondary mixing events and are incorporated into the TISL or form clear-air volumes encompassed by cloudy volumes in the CTMSL. The removal mechanism is efficient enough to keep the CTMSL relatively thin, despite ongoing mixing across the TISL. In a CTEI-prohibiting situation, mixed cloudy parcels are not effectively removed from the CTMSL. The thickness of this layer grows (black dashed arrow between the left and right panel) and it is occupied mostly by diluted cloudy parcels and almost-saturated clearair blobs, which alters profiles of LWC (compare profiles in both panels).

Certainly, this is a simplified picture of the cloud top emerging from analysis of dynamics and thermodynamics only, and shall be expanded in future research. Changes in the profiles of LWC affect radiative transport and, in effect, influence temperature. Droplet collisions in the CTMSL, probably after some time, trigger water removal from the CTMSL by drizzle. Nevertheless, this conceptual model is a step towards untangling a highly complicated problem of entrainment into the STBL.

\section{Conclusions}

High-resolution airborne measurements performed in the course of the POST research campaign allow the division of the cloud-top region into layers: non-turbulent free troposphere, turbulent capping inversion sublayer, turbulent cloudtop mixing sublayer (both forming the entrainment interface layer) and the cloud layer below. Two thermodynamically and microphysically different cases of stratocumulus cloud investigated here show a rather consistent picture of the dynamics. (1) Exchange between the free troposphere and cloud top is governed by turbulent mixing across the inversion. The thickness of the inversion and adjacent cloud-top 


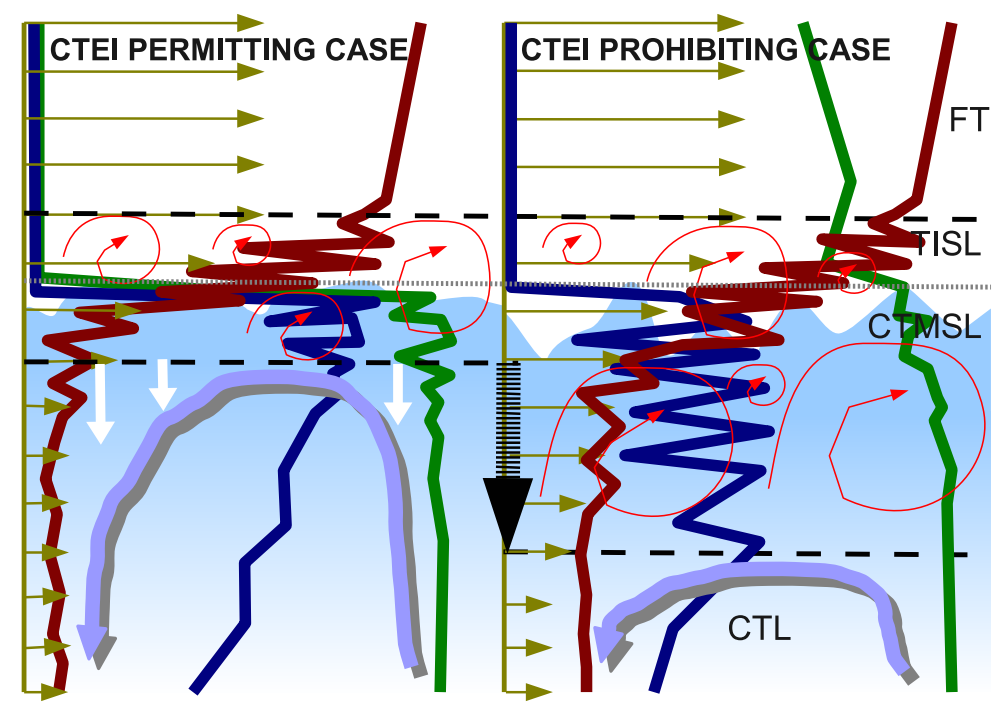

Fig. 16. Cartoon summarizing the main physical mechanisms of mixing in stratocumulus top in CTEI-permitting and -preventing situations. FT - free troposphere; TISL - turbulent inversion sublayer; CTMSL - cloud-top mixing sublayer; CTL - cloud-top layer. $\mathrm{EIL}=\mathrm{TISL}+\mathrm{CTMSL}-$ entrainment interface layer, between black dashed lines. Straight brown arrows - mean wind; thin spiral brown arrows - turbulent eddies due to shear; double violet-grey lines - convective circulations in the STBL; green and blue lines - $\theta_{1}$ and LWC profiles from airborne measurements. White arrows in the left panel indicate removal of negatively buoyant parcels from the EIL in the CTEI-permitting case, while black dashed arrow indicates buildup of the CTMSL in the CTEI-prohibiting case.

mixing sublayer results from dynamic adaptation to temperature (density) and wind jumps between the CTL and the FT (considered here as external factors). Adaptation means here maintaining the Richardson number across the EIL close to its critical value. (2) Effects of the exchange depend on thermodynamic properties of air masses undergoing mixing. When temperature and moisture jumps permit cloud-top entrainment instability, negatively buoyant mixed parcels are removed from the CTMSL region due to negative buoyancy. Resultingly, the CTMSL is thin and cloudy parcels in this layer are almost undiluted. In the CTEI preventing case, mixed parcels often remain cloudy, and buoyancy sorting causes them to remain in the cloud-top region below inversion, making the CTMSL thick. Cloudy parcels in this sublayer exhibit widened droplet spectra and a reduced LWC and droplet number condensation.

Decomposition of the entrainment-mixing process into dynamically driven turbulent mixing across the inversion and the thermodynamic effect of mixing gives a perspective on new entrainment parameterizations, accounting for the efficiency of mixing across a stably stratified turbulent shear layer (Pham and Sarkar, 2010) and the subsequent thermodynamic effects of mixing.

The last remark concerns the STBL capped with inversion without wind shear. Based on detailed numerical studies of cloud top, Mellado et al. (2009) and Mellado (2010) conclude that evaporative cooling effects do not break the inversion and that turbulent mixing enhancement is restricted to the layer of cloud below the inversion. What mechanism is responsible for mixing across a very stable inversion layer? The answer is given in Kurowski et al. (2009), who modeled such a situation, based on the DYCOMS II RF01 case. They found that organized updrafts in the STBL have a kinetic energy far too small to penetrate the inversion and, instead, diverge just below it. This diverging outflow produces shear, capable of inducing turbulence and mixing across the EIL. Figures 7 and 9 in that paper present the details of this process and subsequent removal of mixed parcels by negative buoyancy (CTEI-permitting situation).

Acknowledgements. POST field project was supported by the National Science Foundation with the grant ATM-0735121 and by the Polish Ministry of Science and Higher Education with the grant 186/W-POST/2008/0. We thank all POSTers and CIRPAS for the excellent collaboration during the field campaign. In particular we acknowledge H. Jonsson, who provided CIRPAS data into the POST database, and S. Krueger for inspiring discussions. Analyses presented here were supported by the Department of the Navy Grant N62909-11-1-7061 issued by Office of Naval Research Global (J-LP and MK) and Polish PROZA POIG.01030100/140/08 (SPM) project. SPM acknowledges the "Nature of Turbulence" program at the Kavli Institute for Theoretical Physics; interactions with many colleagues in the course of the program helped to understand cloud-top phenomenology. The United States Government has a royalty-free license throughout the world in all copyrightable material contained herein.

Edited by: T. J. Dunkerton 


\section{References}

Albrecht, B. A., Randall, D. A., and Nicholls, S.: Observations of marine stratocumulus clouds during FIRE, B. Am. Meteorol. Soc., 69, 618-626, doi:10.1175/15200477(1988)069<0618:OOMSCD>2.0.CO;2, 1988.

Andrejczuk, M., Grabowski, W. W., Malinowski, S. P., and Smolarkiewicz, P. K.: Numerical simulation of cloud-clear air interfacial mixing: homogeneous versus inhomogeneous mixing, J. Atmos. Sci., 66, 2493-2500, doi:10.1175/2009JAS2956.1, 2009.

Bretherton, C. S., Uttal, T., Fairall, C. W., Yuter, S. E., Weller, R. A., Baumgardner, D., Comstock, K., Wood, R., and Raga, G. B.: The epic 2001 stratocumulus study, B. Am. Meteorol. Soc., 85, 967977, doi:10.1175/BAMS-85-7-967, 2004.

Carman, J. K., Rossiter, D. L., Khelif, D., Jonsson, H. H., Faloona, I. C., and Chuang, P. Y.: Observational constraints on entrainment and the entrainment interface layer in stratocumulus, Atmos. Chem. Phys., 12, 11135-11152, doi:10.5194/acp-1211135-2012, 2012.

Caughey, S. J., Crease, B. A., and Roach, W. T.: A field study of nocturnal stratocumulus: 2. Turbulence structure and entrainment, Q. J. Roy. Meteor. Soc., 108, 125-144, doi:10.1002/qj.49710845508, 1982.

Chuang, P. Y., Saw, E. W., Small, J. D., Shaw, R. A., Sipperley, C. M., Payne, G. A., and Bachalo, W. D.: Airborne phase Doppler interferometry for cloud microphysical measurements, Aerosol Sci. Tech., 42, 685-703, doi:10.1080/02786820802232956, 2008.

De Roode, S. R. and Wang, Q.: Do stratocumulus clouds detrain? FIRE I data revisited, Bound.-Lay. Meteorol., 122, 479-491, doi:10.1007/s10546-006-9113-1, 2007.

Faloona, I., Lenschow, D. H, Campos, T., Stevens, B., and van Zanten, M.: Observations of entrainment in Eastern Pacific marine stratocumulus using three conserved scalars, J. Atmos. Sci., 62, 3268-3285, doi:10.1175/JAS3541.1, 2005.

Galperin, B., Sukoriansky, S., and Anderson, P. S.: On the critical Richardson number in stably stratified turbulence, Atmos. Sci. Lett., 8, 65-69, doi:10.1002/asl.153, 2007.

Gerber, H., Arends, B. G., and Ackerman, A. S.: A new microphysics sensor for aircraft use, Atmos. Res., 31, 235-252, doi:10.1016/0169-8095(94)90001-9, 1994.

Gerber, H., Frick, G., Malinowski, S. P., Brenguier, J.-L., and Burnet, F.: Holes and entrainment in stratocumulus, J. Atmos. Sci., 62, 443-459, doi:10.1175/JAS-3399.1, 2005.

Gerber, H., Frick, G., Malinowski, S. P., Kumala, W., and Krueger, S.: POST - A New Look at Stratocumulus, 13th Conference on Cloud Physics, Portland, OR, 2010, American Meteorological Society, available at: http://ams.confex.com/ams/ pdfpapers/170431.pdf (last access: 31 July 2013), 2010.

Gerber, H., Frick, G., Malinowski, S. P., Jonsson, H., Khelif, D., and Krueger, S. K.: Entrainment rates and microphysics in POST stratocumulus, J. Geophys. Res.-Atmos., 118, 12094-12109, doi:10.1002/jgrd.50878, 2013.

Grachev, A. A., Andreas, E. L., Fairall, C. W., Guest, P. S., and Persson, O. G.: The critical Richardson number and limits of applicability of local similarity theory in the stable boundary layer, Bound.-Lay. Meteorol., 47, 51-83, doi:10.1007/s10546012-9771-0, 2013.

Haman, K. E., Malinowski, S. P., Kurowski, M. J., Gerber, H., and Brenguier, J-L.: Small scale mixing processes at the top of a ma- rine stratocumulus - a case study, Q. J. Roy. Meteorol. Soc., 133, 213-226, doi:10.1002/qj.5, 2007.

Katzwinkel, J., Siebert, H., and Shaw, R. A.: Observation of a self-limiting, shear-induced turbulent inversion layer above marine stratocumulus, Bound.-Lay. Meteorol., 145, 131-143, doi:10.1007/s10546-011-9683-4, 2012.

Kumala, W., Haman, K. E., Kopec, M. K., Khelif, D., and Malinowski, S. P.: Modified ultrafast thermometer UFT-M and temperature measurements during Physics of Stratocumulus Top (POST), Atmos. Meas. Tech., 6, 2043-2054, doi:10.5194/amt6-2043-2013, 2013.

Kurowski, M. J., Malinowski, S. P. and Grabowski, W. W.: A numerical investigation of entrainment and transport within a stratocumulus-topped boundary layer, Q. J. Roy. Meteorol. Soc., 135, 77-92, doi:10.1002/qj.354, 2009.

Lenschow, D. H., Paluch, I. R., Brandy, A. R, Pearson, R., Kawa, S. R, Weaver, C. J., Kay, J. G, Thornton, D. C., and Driedger, A. R.: Dynamics and Chemistry of Marine Stratocumulus (DYCOMS) experiment, B. Am. Meteorol. Soc., 69, 1058-1067, doi:10.1175/1520-0477(1988)069<1058:DACOMS>2.0.CO;2, 1988.

Lenschow, D. L., Zhou, M., Zeng, X., Chen, L., and Xu, X.: Measurements of fine-scale structure at the top of marine stratocumulus, Bound.-Lay. Meteorol., 97, 331-357, doi:10.1023/A:1002780019748, 2000.

Lilly, D. K.: Validation of a mixed-layer closure. II: Observational tests, Q. J. Roy. Meteorol. Soc., 134, 57-67, doi:10.1002/qj.183, 2008.

Lilly, D. K. and Stevens, B.: Validation of a mixed-layer closure. I: Theoretical tests, Q. J. Roy. Meteorol. Soc., 134, 47-55, doi:10.1002/qj.184, 2008.

Malinowski, S. P., Haman, K. E., Kopec, M. K., Kumala, W., and Gerber, H.: Small-scale turbulent mixing at stratocumulus top observed by means of high resolution airborne temperature and LWC measurements, J. Phys. Conf. Ser., 318, 072013, doi:10.1088/1742-6596/318/7/072013, 2011.

Mellado, J. P.: The evaporatively driven cloud-top mixing layer. J. Fluid Mech., 660, 5-36, doi:10.1017/S0022112010002831, 2010.

Mellado, J. P., Stevens, B., Schmidt, H., and Peters, N.: Buoyancy reversal in cloud-top mixing layers, Q. J. Roy. Meteorol. Soc., 135, 963-978, doi:10.1002/qj.417, 2009.

Moeng, C.-H., Stevens, B., and Sullivan, P. P.: Where is the interface of the stratocumulus-topped PBL?, J. Atmos. Sci., 62, 26262631, doi:10.1175/JAS3470.1, 2005.

Nicholls, S.: The structure of radiatively driven convection in stratocumulus, Q. J. Roy. Meteorol. Soc., 115, 487-511, doi:10.1002/qj.49711548704, 1989.

Nicholls, S. and Turton, J. D.: An observational study of the structure of stratiform cloud sheets: Part 2: Entrainment, Q. J. Roy. Meteorol. Soc., 112, 461-480, doi:10.1002/qj.49711247210, 1986.

Pawlowska, H., Brenguier, J.-L., and Burnet, F.: Microphysical properties of stratocumulus clouds, Atmos. Res., 55, 15-23, doi:10.1016/S0169-8095(00)00054-5, 2000.

Peltier, W. R. and Caulfield, C. P.: Mixing Efficiency in stratified shear flows, Annu. Rev. Fluid. Mech., 35, 135-167, doi:10.1146/annurev.fluid.35.101101.161144, 2003. 
Pham, H. T. and Sarkar, S.: Transport and mixing of density in a continuously stratified shear layer, J. Turbul., 11, 1-23, doi:10.1080/14685248.2010.493560, 2010.

Siebert, H., Lehmann, K., Wendisch, M., Franke, H., Maser, R., Schell, D., Saw, E.-W., and Shaw, R. A.: Probing Finescale Dynamics and Microphysics of Clouds with HelicopterBorne Measurements, B. Am. Meteorol. Soc., 87, 1727-1738, doi:10.1175/BAMS-87-12-1727, 2006.

Smyth, W. D. and Moum, J. N.: Length scales of turbulence in stably stratified mixing layers, Phys. Fluids, 12, 1327-1342, doi:10.1063/1.870385, 2000.

Stevens, B.: Entrainment in stratocumulus-topped mixed layers, Q. J. Roy. Meteorol. Soc., 128, 2663-2690, doi:10.1256/qj.01.202, 2002.

Stevens, B.: Atmopsheric moist convection, Annu. Rev. Earth. Pl. Sc., 33, 605-643, doi:10.1146/annurev.earth.33.092203.122658, 2005.

Stevens, B., Lenschow, D. H., Vali, G., Gerber, H., Bandy, A., Blomquist, B., Brenguier, J-L., Bretherton, C. S., Burnet, F., Campos, T., Chai, S., Faloona, I., Friesen, D., Haimov, S., Laursen, K., Lilly, D. K., Loehrer, S. M., Malinowski, S. P., Morley, B., Petters, M. D., Rogers, D. C., Russell, L., SavicJovcic, V., Snider, J. R., Straub, D., Szumowski, M. J., Takagi, H., Thornton, D. C., Tschudi, M., Twohy, C., Wetzel, M., and van Zanten, M. C.: Dynamics and chemistry of marine stratocumulus - Dycoms II, B. Am. Meteorol. Soc., 84, 579-593, doi:10.1175/BAMS-84-5-579, 2003.
Turner, J. S.: Turbulent entrainment: the development of the entrainment assumption, and its application to geophysical flows, J. Fluid. Mech., 173, 431-471, doi:10.1017/S0022112086001222, 1986.

Wang, S., Golaz, J.-C., and Wang, Q.: Effect of intense wind shear across the inversion on stratocumulus clouds, Geophys. Res. Lett., 35, L15814, doi:10.1029/2008GL033865, 2008.

Wang, S., Zheng, X., and Jiang, Q.: Strongly sheared stratocumulus convection: an observationally based large-eddy simulation study, Atmos. Chem. Phys., 12, 5223-5235, doi:10.5194/acp-125223-2012, 2012.

Wood, R.: Stratocumulus clouds, Mon. Weather Rev., 140, 23732423, doi:10.1175/MWR-D-11-00121.1, 2012.

Yamaguchi, T. and Randall, D. A.: Large-Eddy simulation of evaporatively driven entrainment in cloud-topped mixed layers, J. Atmos. Sci., 65, 1481-1504, doi:10.1175/2007JAS2438.1, 2008. 